\title{
Aliyatu Al-Tamasuki Al-Nashyi fi Al-Qurani Al-Karimi Wa Dalalutuha fi Tafsiri Al-Kassyafi
}

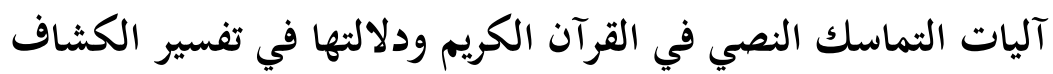

Osamah Saleh Mohammed Allbail

osama-1401@hotmail.com

Arabic Language and Literature Department

King Saud University, Saudi Arabia

\section{Rijal Mahdi}

rijal_mahdi0123@yahoo.co.id

Arabic Language and Literature Department IAIN Syekh Nurjati Cirebon, Indonesia

• Received: 06.05.2020 • Accepted: 21. 10.2020 • Published online: 24.11 .2020

Abstract: This research aims to highlight the importance of context and its role in the coherence of the text and describe the coherence mechanisms revealed by Al-Zamakhshari during his interpretations. Al-Zamakhshari is considered one of the first who follow this aspect. The context is in its fate, giving it multiple meanings or limiting it to one meaning, and among the mechanisms mentioned by Al-Zamakhshari is the referral listing types and indicating its importance. The mechanisms are repetition and sympathy, and all of this will become clear during the research. The research followed a descriptive approach, but it did not remain a captive to it, but tried to benefit from other approaches as much as possible. The research has drawn conclusions from them; First: Although al-Zamakhshari mention the word context only a few times, he used it a lot during his interpretation, as he deal with most contextual phenomena in an approach that reveals Zamakhshari's awareness of the importance of context in understanding the meaning. Second: Al-Zamakhshari realized the importance of text cohesion, and what repetition and referral bring about linking the text to each other. He took care of the assignee and the multiplicity of the assignee, which leads to the coherence of the text, this does not mean that he left it unchecked or restricted as he stresses the importance of taking into account the internal context and taking into account the Qur'anic systems. And its linguistic function, and its usefulness for the addresses, as Zamakhshari believes that repetition is rhetorical unless it benefits the reader, 
or the speaker wants to deliver a message to the reader through him. Third: AlZamakhshari paid great attention to conjunctions, and al-Zamakhshari showed the ability of conjunctions to connect parts of the text.

Keywords: Context, Cohesion, Temporal, Al-Zamakhshari, Referra

الملخص: يهدف هذا البحث إلى إبراز أهمية السياق ودوره في ترابط النص وتناسقه ووصف آليات التماسك التي كشف عنها الزمخشري أثناء تفسيره، ويعد الزمخشري من السباقين إلى تتبع هذا الجانب، فقد أولى هذا التماسك عناية فائقة، إذ ذهب إلى إبراز روابط النص، ودلالة

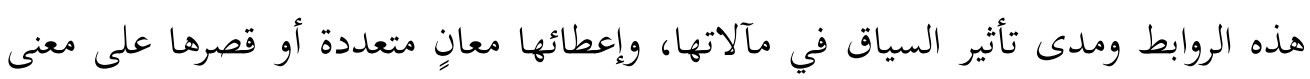
واحد، ومن الآليات التي ذكرها الزمخشري الإحالة معددا أنواعها ومبينا أهميتها ومن الآليات التكرار والعطف وسيتضح كل ذلك أثناء البحث. وقد اتبع البحث منهجا وصفيا، ولكنه لم

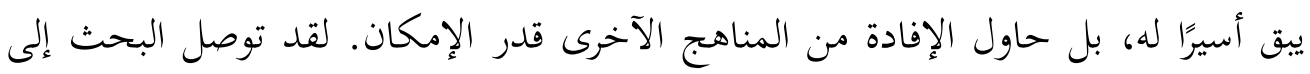
نتائج منها؛ أولا: على الرغم من أن الزمخشري لم يذكر لفظ السياق إلا بضع مرات، إلا أنه

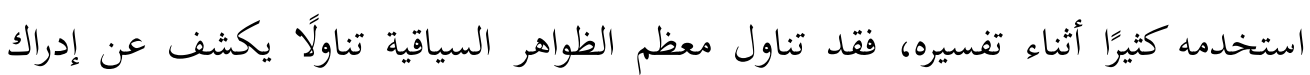

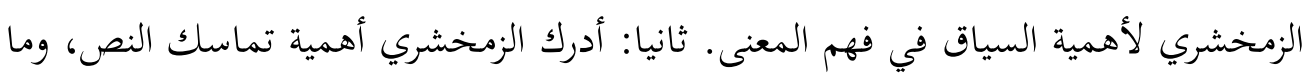
يحدثه التكرار والإحالة من ربط النص بعضه ببعض. وقد اعتنى بالمحال والمحال إليه وبتعدد

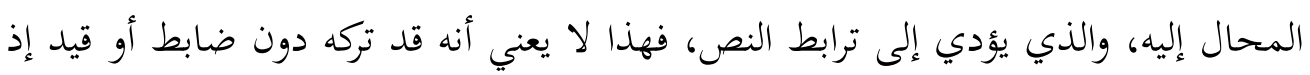

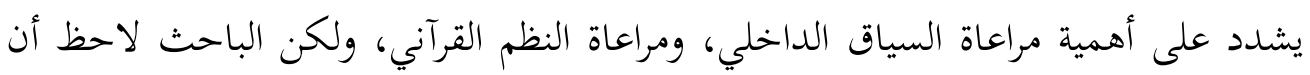
الزمخشري حينما تناول ظاهرة التكرار تناوله من جانب المعنى، ووظيفته اللغوية، وفائدته بالنسبة للمخاطب، إذ يرى الزمخشري أن التكرار يعد لغوًا إلا إذا أفاد فائدة للقارئ، أو أراد

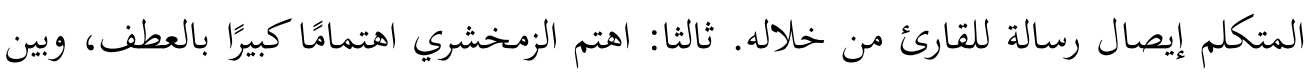
الزمخشري قدرة العطف على ربط أجزاء النص، ولم يكتف بذلك بل إنه كان يحدد دلالة حروف العطف وأسباب اختيارها. كلمات دلالية: السياق، التماسك، الزمخشري، الإحالة 
Osamah Saleh Mohammed Allbail, Rijal Mahdi

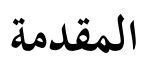

القرآن الكريم كتاب الله، نزل بلسان عربي مبين، وهو معين لا ينضب، والقرآن الكريم

المصدر الأول في التشريع الإسلامي ولا تتبين الأحكام الشرعية إلا بفهم صحيح للنص القرآني ولا يتأتى ذلك إلا من خلال مراعاة ما يحيط النص من ملبسات وأسباب ومقاصد النزول، فاللفظ قد يتعدد معناه خارج السياق، فإذا وضع في سياق ما، فإنه يدل على معنى واحد، ولذلك قال ابن الانباري: إن كلام العرب يصحح بعضه بعضًا، ويرتبط أوله بآخره ولا يعرف معنى الخطاب منه إلا باستيفائه واستكمال جميع حروفه، فجاز وقوع اللفظة على المعنيين المتضادين، لأنها يتقدهُها ويأتي بعدها ما يدل على خصوصية أحد المعنيين دون الآخر، ولا يراد بها في حال التكلم والإخبار إلا معنى واحد.Al-Anbari, 1987) إن نظرية السياق تعد "من النظريات العملية الأكثر تعلقًا بالنظام اللغوي، بل إنها بطريقتها الإجرائية في تحديد جملة السياقات وما يصاحبها من العوامل الخارجية كالمقام والحال، تعد بذلك مرحلة تمهيدية مهمة بالنسبة للنظرية التحليلية" (Al-Jalil, 2001) إذ يمكن لنا بواسطتها أن نعرف الترادف، ونحدد المعنى الدقيق للكلمة، فالسياق هو وحده الذي يدلنا على معنى كلمة (عين) إذا كان بمعنى العضو الموجود في الإنسان، أو بمعنى الماء، أو بمعنى الجاسوس، وهكذا، ولذا فمعنى الكلمة يكمن في استعمالها، ولا يمكن أن تفهم إلا من خلال (Ahmed, السياق وعلاقتها مع الكلمات الأخرى لأنه من أهم القرائن الدالة على المعنى (2017بغض النظر إلى أنه من المصطلحات الأصيلة له جزوره في التراث العربي أو أنه من المصطلحات الجديدة والغريبة التي أتنجته الحضارة الغربية (Al-Bustani, 2011)

$$
\text { كمصطلحات النص، والخطاب، والسياق أو غيرها. }
$$

ويمكن أن يعرف السياق بأنه إطار عام تنتظم فيه عناصر النص ووحداته اللغوية، ومقياس تتصل بوساطته الجمل فيما بينها، وبيئة لغوية وتداولية، ترعى مجموع العناصر المعرفية التي 
Osamah Saleh Mohammed Allbail, Rijal Mahdi

يقدمها النص للقارئ. ويضبط السياق حركات الإحالة بين عناصر النص، فلا يفهم معنى كلمة أو جملة، إلا بوصلها بالتي قبلها، أو بالتي بعدها داخل إطار السياق.)(Budar’u, n.d.) ولقد أولى المفسرون السياق عناية كبرى وكان لهم النصيب الأوفر(Bakhulah, 2018) في مقاربة النص القرآني وجعلوا له مكانته العالية في استجلاء المعنى القرآني وبيانه، وقد كان الزمخشري أحد هولاء الذين اهتموا بالسياق القرآني واعتمد عليه في كتابه الكشاف، الذي يعد من أهم كتب التفسير بغض النظر إلى آراء العلماء حول هذا التفسير الذي فيه دسائس الاعتزال (Faraj, 2019) على رأي البعض أو الثناء عليه لأنه كان في غاية المعرفة بفنون البلاغة وتعريف الكلام عند الآخر، وكان متجها إلى إظهار ما في القرآن الكريم من ثروة لغوية وبلاغية (Al-Zyout, 2019). فقد ذهب الزمخشري يستجلي المعنى ويبين ما في القرآن من أسرار، معتمدًا في ذلك على ثقافته اللغوية، ولهذا سيكون الكشاف هو ميدان البحث، وسيكون موضوعه خاصًا بدراسة السياق وأثره في تماسك النص، وما يوحي به من دلالات، من أجل الوصول إلى معرفة أثر السياق في استجلاء المعاني والدلالات عند الزمخشري. وقد جاء اختيار الزمخشري ميدانا للبحث لمكانته وما له من باع طويل في اللغة والتفسير والبلاغة، ويعد كشافه عمدة في بيان بلاغة القرآن الكريم، فأغلب من جاء بعده قد نهلوا من كشافه. منهجية البحث

تتبع الباحث الآيات التي كان للسياق دور فيها في توجيه المعنى لدى الزمخشري في الكشاف. وقد اتبع الباحث في بحثه هذا المنهج الوصفي، ولكنه لم يبق أسيرًا له، بل حاول الإفادة من المناهج الآخرى قدر الإمكان. والبحث هذا لا يهدف إلى الموازنة بين ما عند الزمخشري وما عند غيره من المحدثين، لإدراك الباحث بعدم موضوعية الموازنة لاختلاف الزمان والظروف. 
Osamah Saleh Mohammed Allbail, Rijal Mahdi

نتائج الدراسة وتحليلها

آليات التماسك النصي

القرآن الكريم وحدة متكاملة، ونسيج متماسك يمثل معجزة السماء الكبرى إذ تتجلى فيه أبها مستويات الخطاب اللغوي وأجمل بنائات الفن المقالي .Al-Mihana, 2017) ومن هذه الآليات التي ذكرها وبين أثرها ودلالتها الآتي: أولا: الإحالة

وهي علاقة بين عنصر لغوي وآخر، بحيث يتوقف تفسير الأول على الثاني. ومن الإحالة: الضمائر

ف"لا يخفى الدور الذي تقوم به الإحالة، ضميرية أو إشارية أو موصولي في ربط أجزاء خطاب معين، وقد اهتم المفسرون بهذا الدور(Al-Umusy, 2018) ومن هولاء المفسرين الزمخشري فقد تتبع " حركة الضمائر في الخطاب القرآني ودلالتها، وإحالة الضمير، وتعدد المحال إليه(Al-Umusy, 2018)"، حيث يختلف المعنى، ويتعدد بتعدد المحال إليه. فالضمير قد يشير إلى عنصر واحد فقط، إذا دل السياق على هذا المحال إليه، نحو قوله تعالى : (فَأَلَّلَهُمَا الشَّنَطَانُ عَنْها) [البقرة: 36] إذ يحيل الزمخشري الضمير في (عنها) إلى الشجرة -Az) (Zamakhsyarī, 2009) والشجرة مذكورة في آية سابقة مع احتمالية أن يعود الضمير على الجنة، وهي مذكورة في نفس الآية التي ذكرت فيها الشجرة، ولكن الزخشري حصر الإحالة على الشجرة، وعليه يكون معنى حرف الجر (عن) هي السببية أي أوقعها بسبب الشجرة.

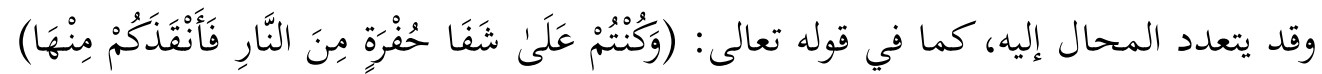
[آل عمران: 103] إذ يذكر الزمخشري في عودة الضمير (منها) ثلاثة احتمالات، دون ان يرجح (Az-Zamakhsyarī, واحدًا منها على الآخرين، وهذه الاحتمالات هي الحفرة أو النار أو الشفا كيات 
Osamah Saleh Mohammed Allbail, Rijal Mahdi

(2009 وكل واحد منها مذكور ضمن الآية نفسها، وإذاكانت كلمتا الحفرة والنار متطابقتين مع الضمير العائد، فإن الشفا، و إن جاء مذكرًا إلا أنه اكتسب التأنيث من خلال اضافته إلى لى الحفرة.

ومن الأمثلة التي يتعدد فيها المحال إليه، قوله تعالى: (فَلَال يَصُدَّنَّكَ عَنْهَا مَنْ لَا يُؤِْْنُ بِهَها وَاتَّبَعَ هَوَاهُ فَتَرْدَىن) [طه: 16] فهنا يحيل الزمخشري الضمير في (عنها) " للقيامة ويجوز أن يكون للصلاة"، فنحن أمام احتمالين جائزين، الأول عودة الضمير على القيامة، ولفظ القيامة هو المذكور المتأخر، والثاني هو عودة الضمير على الصلاة، وهي مذكورة في الآية رقم (14)، وهنا نجد الضمير مطابقًا للمحال إليه في الاحتمالين (القيامة والصلاة) إلا أن الأرجح هو عودة الضمير على القيامة؛ لأنها أقرب إليه من الصلاة.

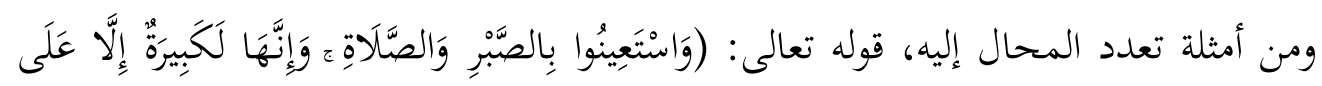
الْخَاشِعِينَ) [البقرة: 45] إذ يذكر الزمخشري أن الضمير " للصلاة أو الاستقامة، ويجوز أن

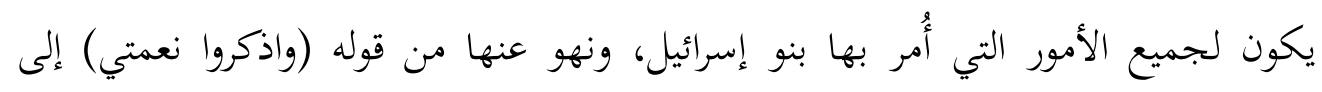
(واستعينوا).(Az-Zamakhsyarī, 2009)" فمرجعية الضمير هنا، فيه ثلاثة احتمالات، الأول عودة الضمير على الصلاة، وهي أقرب مذكور، والثاني عودته إلى الاستقامة، وكلا الاحتمالين مذكوران في الآية نفسها، وبين الضمير والمحال إليه تطابق في الإفراد والتأنيث، أما الاحتمال الثالث في رأي الزمخشري، فهو إمكانية أن يعود الضمير إلى الأمور التي أمر الله بها بني إسرائيل، وهذا يستغرق خمس آيات، ويتضمن أمور عدة موزعة بين الأوامر والنواهي، ومن هذه الأمور ذكر النعمة، والوفاء بالعهد، ورهبة الله، والإيمان برسالة محمد صلى الله عليه وسلم، وألا يشتروا بآيات الله ثمنًا قليلا، وتقوى الله، ولا يلبسوا الحق بالباطل وسلوك سبيل البر. ونخلص من هذا إلى أن الإحالة الضميرية عند الزمخشري نوعان: إحالة إلى عنصر متقدم وهو الأغلب، وإحالة إلى خطاب سابق.(Al-Umusy, 2018) 


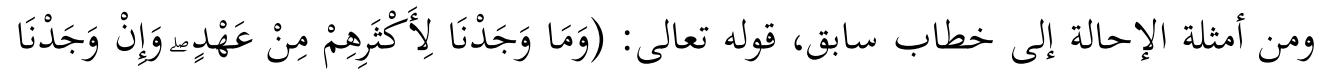
أَكَثَرَهُمْ لَفَاسِقِينَ) [الأعراف: 102] حيث يرى الزمخشري أن الضمير في (لأكثرهم)، عائد على جنس الناس جمعيًا، والمعنى هنا وما وجدنا لأكثر الناس من عهد، فأكثر الناس نقض عهد الله وميثاقه في الايمان والتقوى، ويجوز أن يعود الضمير إلى الأمم المذكورين في السورة وهذا يمتد من الآية (59) إلى الآية (102) (Az-Zamakhsyarī, 2009)، وهذا يعني احتمال عودة الضمير إلى جنس الناس، وعلى هذا تكون دلالة الآية تعميم نقض عهد الله على أغلب الناس منذ آدم حتى قيام الساعة، أو عودته على الأمم المذكورة في السورة، وعلى هذا يكون التعميم مقتصرًا على أكثر الأمم المذكورة في السورة. والمتأمل في الأمثلة السابقة - ومثلها كثير - يجد أن الزخشري لا يرجح عودة الضمير إلى واحد منها، بل يمجَّوز عودة الضمير على عناصر متعددة، وهذا يعني إمكانية عودة الضمير عليها كلها مجتمعة. فتعدد المحال إليه يؤدي إلى اتساع المعنى، واحتمالية اختلافه في كل

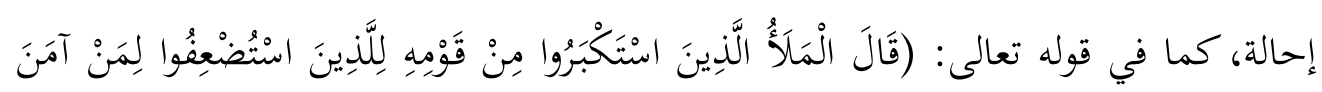

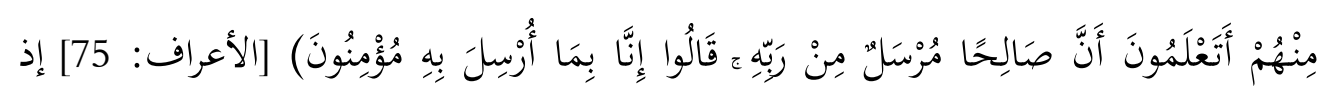
يحتمل أن يعود الضمير في (منهم) على (قومه)، ويحتمل أن يعود على (الذين استضعفوا)،

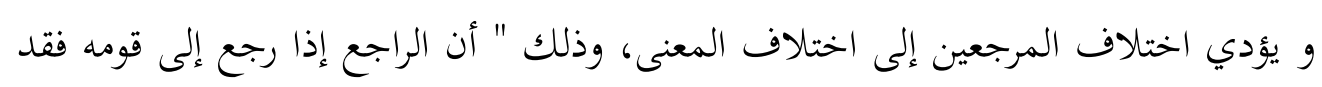
جعل (مَنْ ءمَنَ) مفسرًا لمن استضعف منهم، فدل أن استضعافهم كان مقصورًا على المؤمنين، وإذا رجع إلى الذين استضعفوا، لم يكن الاستضعاف مقصورًا عليهم، ودلّ أن المستضعفين كانوا مؤمنين وكافرين (Az-Zamakhsyarī, 2009). فاختلاف المرجع أدى إلى اختلاف المعنى، فالعلاقة بين المرجعين علاقة خصوص وعموم، فإذا عاد الضمير إلى قومه فقد خص الاستضعاف على من آمن، أما لو رجع إلى (الذين) فقد عم المؤمنين والكافرين في الاستضعاف. 
Osamah Saleh Mohammed Allbail, Rijal Mahdi

وإذا كان الزمخشري في الأمثلة السابقة، قد جَّوز تعدد المحال اليه دون أن يرجح واحداً منها، فإنه ينقل إلينا عدة آراء في تعدد المحال إليه ويرجح واحدًا منها على الأخرى، نحو قوله

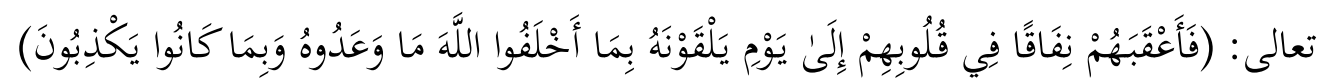
[التوبة: 77] إذ ينقل الزمخشري رأي الحسن وقتادة في أن الضمير في (يلقونه) عائد على البخل، ويعني هذا فأورثهم نفاقًا متمكنًا (في قلوبهم) ثم يورد لنا رأيه ويرجحه، وهو أن الضمير عائد على لفظ الجلالة (الله)، والمعنى فخذلهم حتى نافقوا وتمكن في قلوبهم نفاقهم فلا ينفك عنها إلى أن يموتوا بسبب إخلافهم ما وعدو الله به (Az-Zamakhsyarī, 2009). ونجد أن الضمير في قول الحسن وقتادة، قد عاد إلى اقرب مذكور، أما الزمخشري فيرجعه إلى أول المذكورين، وفي هذا الترجيح لا يبين الزمخشري سبب ترجحيه، ولكنه في مواطن أخرى يبين السبب في ذلك، ومن الأمثلة التي بين فيها الزمخشري سبب ترجحيه، أو قصره الضمير على لى

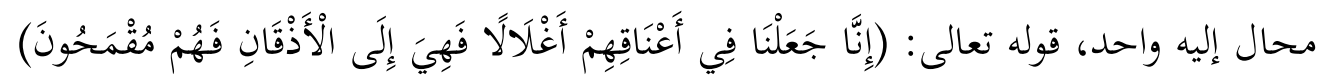
[يس: 8] إذ يرى الزمخشري أن الضمير في قوله (فهي) عائدًا على الأغلال، ويجعل دليله في ذلك قوله (فهم مقمحون)، ويرد على من جعل الضمير عائد على الأيدي، بقوله " ألا ترى كيف جعل الإقماح نتيجة قوله: (فَهََْ إلَّى الأْفَقَانِ) ولو كان الضمير للأيدي لم يكن معنى التسبب في الإقماح ظاهرًا، على أن هذا الإضمار فيه ضرب من التعسف، وترك الظاهر الذي يدعوه المعنى إلى نفسه إلى الباطن الذي يجفو عنه، وترك الحق الأبلج إلى الباطل اللجلج. فإن قلت: فقد قرأ ابن عباس رضي الله عنهما: (في أيديهم) وابن مسعود: (في أيمانهم)، فهل تجوّز على هاتين القرآثين أن تجعل الضمير للأيدي أو للأيمان؟ قلت: يأبى ذلك، وإن ذهب الإضمار المتعسف ظهور كون الضمير للأغلال، وسداد المعنى عليه كما ذكرت-Az).

Zamakhsyarī, 2009). 
Osamah Saleh Mohammed Allbail, Rijal Mahdi

فهنا نجد الزمخشري يقصر عودة الضمير على عائد واحد "لأنها هي المحدث عنها، ومعنى هذا الترتيب بالفاء أن الغل لغلظه وعرضه يصل إلى الذقن؛ لأنه يلبس العنق جميعه-Al)" فلا سبيل لعودة الضمير للأيادي، لأنه ضرب من التعسف وترك المعنى Halabi, n.d.) الظاهر، و الذي دل على رجوع الضمير إلى الأعناق، أن "الاغلال واصلة إلى الاذقان ملزوزة (Az-Zamakhsyarī, 2009) إليها. . . فلا تخليه يطأطئ رأسه ويوطئ قذاله، فلا يزال مقمحًا أما من جعل الضمير عائدًا على الأيدي، فدليلهم أن الغل لا يكون إلا في العنق واليدين، ولذلك سمي القيد جامعة، ولم تذكر الأيدي، لأنها مفهومة من هذه الملازمة في هذه الآلة، بين العنق واليدين فالعلاقة علاقة ملازمة، أما الزمخشري فيجعل العلاقة نتيجة بعد سبب-Al). Halabi, n.d.)

وقد يرجح الزمخشري أحد المحالات إليه بناءً على قراءة وردت، كما في قوله تعالى: (تَبَاركَكَ

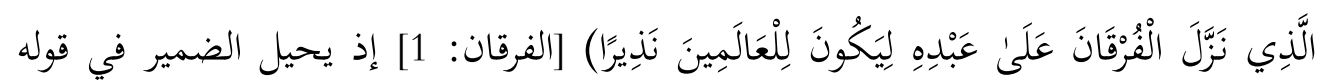
(ليكون) إلى (عبده)، وهو الأقرب، ويمكن أن يعود على الفرقان ويعضده - كما يقول - قراءة ابن الزبير(Az-Zamakhsyarī, 2009)، فالأرجح هو عودة الضمير على الفرقان لأن قراءة ابن الزبير جاءت بجمع عبده (Khlawaih, 2009)، ولا يطابق الضمير هذه القراءة؛ لأن الضمير العائد مفرد.

ويرى الزمخشري أن الضمير يمكن أن يعود على شيء غير مذكور، كما في قوله تعالى:

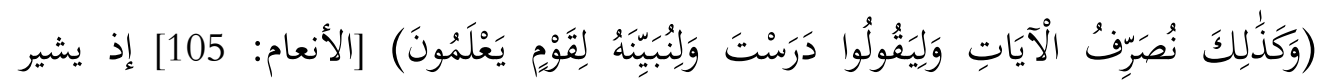
الزمخشري إلى إمكانية عودة الضمير في "لنبينه " إلى القرآن، وإن لم يجر له ذكر، لكونه معلومًا، مع إمكانية عودة الضمير إلى الآيات أو إلى التبيين (Az-Zamakhsyarī, 2009)، والذي جعل إمكانية عودة الضمير إلى شيء غير مذكور هو قدرة المخاطَب على معرفة المحال

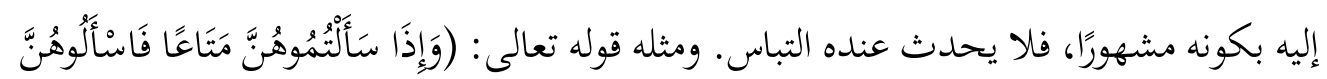


مِنْ وَرَاءٍ حِجَابٍ) [الأحزاب: 53] إذ يرى الزمخشري أن الضمير (هن) عائد على نساء النبي، وإن لم يذكرن؛ لأن الحال ناطقة بذكرهن . Az-Zamakhsyarī, 2009) فنساء النبي لم يذكرن في الآية، ولكن الآية تتحدث عن بيوت النبي صلى الله عليه وسلم، فالسياق العام للآيةٍ [من موضوع الخطاب، وسبب النزول، والمكان المذكور في الآيةٍ ] يدل على المحال إليه، ولا يحتاج القارئ إلى بحث، ولا يمكن أن يحدث عنده نوع من اللبس. وإذاكان الزخشري في الأمثلة السابقة، قد بين إمكانية عودة الضمير على شي لم يرد في اللفظ، ولكنه معلوم، أو يدل عليه السياق العام للنص، فإنه قد يحيل الضمير إلى مبهم غير معلوم، نحو قوله تعالى:

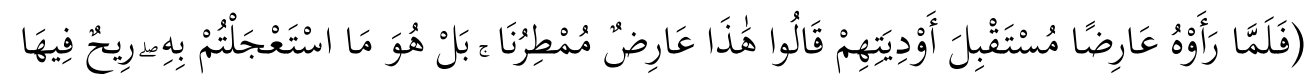
عَذَابُ أَلَيِمْ) [الأحقاف: 24] إذ يرى الزمخشري أن الضمير في قوله (فَلَمَّا رَأَوْهُ)، فيه وجهان: أن يرجع إلى (ما تعدنا)، وأن يكون مبهمًا قد وضح أمره بقوله تعالى: (عارضنا)(Az) Zamakhsyarī, 2009).

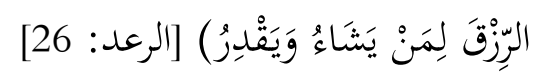

إذ يقول الزمخشري: "فإن قلت: الذي رجع إليه الضمير في قوله: (وَيَقْدِرُ لَهُ) هو من يشاء، فكأن بسط الرزق وقدره جعلا لواحد. قلت: يحتمل الوجهين جميعًا: أن يريد ويقدر لمن يشاء، فوضع الضمير موضع من يشاء، لأن (مَن يَشَآء) مبهم غير معين، فكان الضمير مبهمًا مثله، وأن يريد تعاقب الأمرين على واحد على حسب المصلحة" فقد تعددت المعاني بتعدد المحال إليه، فالمعنى على الاحتمال الأول: أن البسط يصيب بعضًا من الناس في حين يصيب القتر البقية، و المعنى على الاحتمال الثاني: أن يتعاقب بسط الرزق وقتره على الشخص نفسه، وكلا الاحتمالين جائز. 
Osamah Saleh Mohammed Allbail, Rijal Mahdi

ونخلص من هذا كله أن تعدد الإحالة جائز ومبرر عند الزمخشري، فقد يفرضه المعنى، وقد تفرضه القرائن سواء كانت نحوية أو سياقية.

وإذا كان الزمخشري قد عُني بتعدد المحال إليه، والذي يؤدي إلى ترابط النص، فهذا لا يعني أنه قد تركه دون ضابط أو قيد، فقد أشار إلى أهمية مراعاة السياق الداخلي، ومراعاة النظم

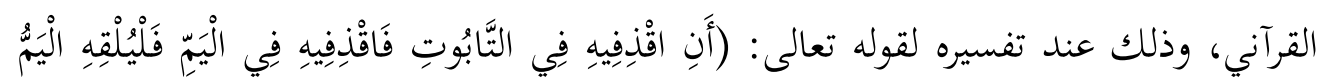

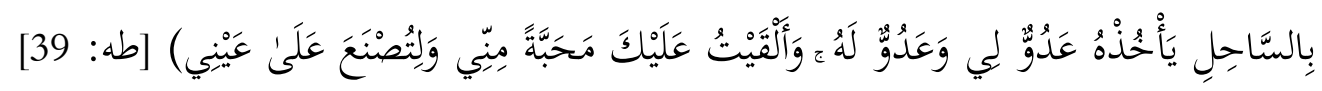
إذ يقول: "والضمائر كلها راجعة إلى موسى، ورجوع بعضها إليه، وبعضها إلى التابوت فيه هجنة؛ لما يؤدي إليه من تنافر النظم. فإن قلت: المقذوف في البحر هو التابوت، وكذلك الملقى إلى الساحل. قلت: ما ضرك لو قلت: المقذوف والملقى هو موسى في جوف التابوت، حتى لا تفرق الضمائر، فيتنافر عليك النظم الذي هو أم إعجاز القرآن، والقانون الذي وقع عليه التحدّي، ومراعاته أهم ما يجب على المفسر. (Az-Zamakhsyarī, 2009) فالزمخشري في النص السابق يقصر الإحالة على محال إليه واحد، رغم تعدد الضمائر؛ لأن تعدد المحال إليه هنا قد يؤدي إلى تنافر النظم، فلا يمكن أن يكون الضمير في قوله (اقذفيه في التابوت) لموسى، ثم يكون الضمير في قوله (فاقذفيه في اليم) للتابوت ثم تعود الإحالة في قوله (يأخذه) إلى موسى، فذلك يؤدي إلى تنافر النظم و تفكيكه. وإذا ورد ما يشير إلى عدم توأمة الضمائر مع المخاطب، أو مع المحال إليه، فإن الزمخشري سرعان ما يبرر ويوضح سبب المخالفة. ومن الأمثلة على ذلك، قوله تعالى: (قَالَ إِنَّمَا أُوِتيتُهُ

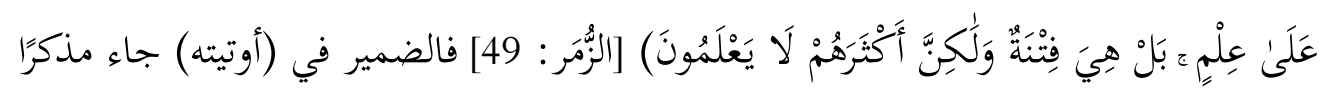
في حين جاء في (هي) مؤنثًا حملاً على المعنى أوّلاً، وعلى اللفظ آخرًا؛ ولأنّ الخبر لما كان (Az-Zamakhsyarī, 2009) - مؤنثًا أعني (فِتْنَةً) ساغ تأنيث المبتدأ لأجله لأنه في معناه بحسب رأي الزمحشري - فتذكيره حماً على المعنى، وتأنيثه حملاً على اللفظ. 


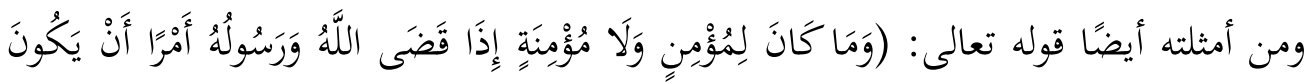

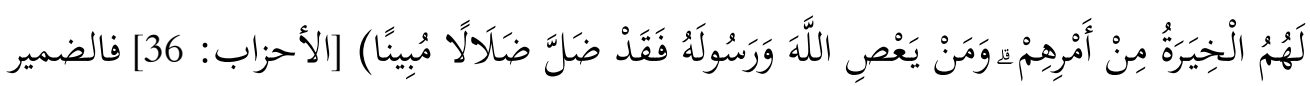
(هم) جاء جمعًا، وحقه أن يوحد، نحو قولك ما جاءني من رجل و لا امرأة إلا كان من شأنه كذا، فيبرر الزمخشري هذا بقوله إنهما وقعا تحت النفي فعما كل مؤمن ومؤمنة، فرجع الضمير على المعنى لا على اللفظ (Az-Zamakhsyarī, 2009). فدلالة العموم التي تضمنتها كلمتا (مؤمن ومؤمنة) جعلت الضمير يرجع مجموعًا لا مفردًا، فالعلة علة معنوية. ومن الأمثلة التي جاء المحال غير مطابقٍ للمحال إليه، قوله تعالى: (وَالَّذِينَ يَكْنْزونَ الذَّهَبَ

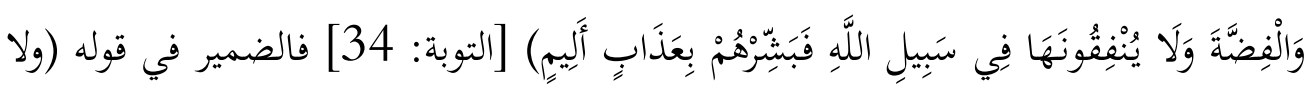
ينقونها) يعود على الذهب والفضة إلا أنه جاء موحدًا، ولم يثنَ "ذهابًا بالضمير إلى المعنى (Az-Zamakhsyarī, دون اللفظ؛ لأن كل واحد منهما جملة وافية وعدة كثيرة ودنانير ودراهم

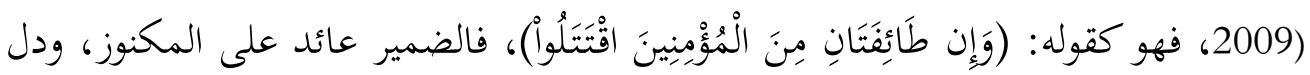
على هذا جزؤه المذكور لأن المكنوز أعم من التعدين، فلما ذكر الجزء دل على الكل، فعاد الضمير جمعًا لهذا الاعتبار(Al-Halabi, n.d).

وقد لا يجزم الزمخشري برأي معين في تبيين سبب عدم المطابقة، ومن أمثلة ذلك ما ذهب

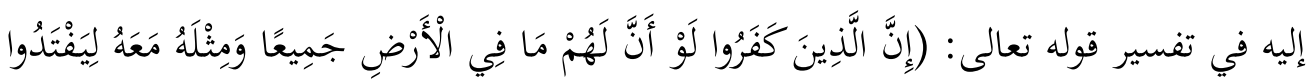

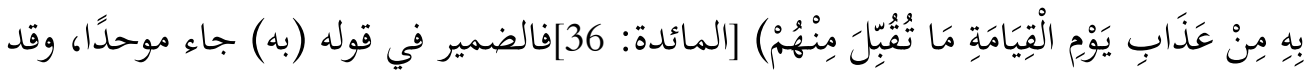
ذُكرِرَ قبله شيئان، ويرجع الزمخشري ذلك إلى عدة احتمالات، الاحتمال الأول: أنه حصل في الآية حذف، حيث حذف من الأول لدلالة الثاني عليه، ويكون المعنى لو أن لهم ما في الأرض ليفتدوا به ومثله معه ليفتدوا به. أما الاحتمال الثاني فيرجعه إلى تبادل الوظائف، فأجري الضمير مجرى اسم الإشارة، كأنه قيل ليفتدوا بذلك. وأما الاحتمال الثالث فهو أن تكون الواو في (مثله) بمعنى مع فيتوحد المرجوع إليه (Az-Zamakhsyarī, 2009). 
وقد تكون علة المخالفة هي علة لفظية فقط، ومن أمثلته قوله تعالى : (وَإِنَّهُمْ لَيَصُدُّونَهُمْ عَنِ

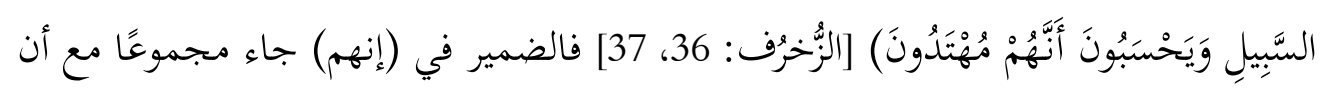
الحديث قبله عن المفرد، والسبب في ذلك في رأي الزخششري " أنّ (من) مبهم في جنس العاشي، وقد قيض له شيطان مبهم في جنسه، فلما جاز أن يتناولا لإبهامهما غير واحدين: جاز أن يرجع الضمير إليهما مجموعًا (Az-Zamakhsyarī, 2009) فالعلاقة علاقة مشابهة لفظية فحرف الجر (من) لفظ مبهم، يجوز أن يتناول المجموع، ولما كان كذلك قيض الله للعاصي شيطان مبهم.

وقد يدل أحد المحالين إليهما، على الآخر، فيكتفى بأن يعود الضمير إلى أحدهما، ومن

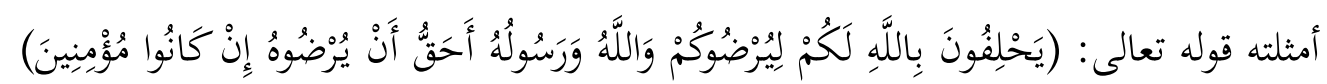
[التوبة: 62] فالضميرفي (يرضوه) جاء دالًا على مفرد وتوحيد الضمير فيه؛ لأنه لا تفاوت بين رضا الله ورضا رسوله (صلى الله عليه وسلم)، فكانا في حكم مرضيّ واحد-Az) Zamakhsyarī, 2009) وقد يذكر الضمير و يؤنث في الدلالة على شيء واحد، نحو قوله تعالى: (وَإِنْ كَانَ قَمِيصُهُ قُدَّم

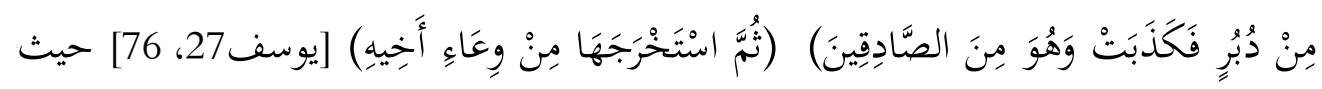
جاء الضمير في (به) في الآية الأولى مذكرًا، في حين جاء في (استخرجها) في الآية الثانية مؤنثًا، مع أن الصواع هو المحال إليه في كلا الموضعين، فما سبب ذلك؟ يجيب الزمخشري عن ذلك بقوله: " قالوا رجع بالتأنيث على السقاية، أو أنث الصواع، لأنه يذكر ويؤنث، ولعلّ يوسف كان يسميه سقاية وعبيده صواعًا، فقد وقع فيما يتصل به من الكلام سقاية، وفيما يتصل بهم منه صواعًا (Az-Zamakhsyarī, 2009). وهنا نجد الزمخشري يقدم ثلاثة احتمالات، الأول والثاني منها لفظيان، والثالث يرجعه إلى السياق الحواري الذي ورد فيه، 
فالتذكير جاء على لسان عبيده الذين يذكَّرونه، والثاني على لسان يوسف الذي يؤنثه، لذا جاء مؤنثًا، فاختلاف اللهجات أدى إلى اختلاف نوع الضمير. وقد يرجع الزمخشري سبب عدم المطابقة إلى العلاقة بين المتكلم والمخاطب، نحو قوله

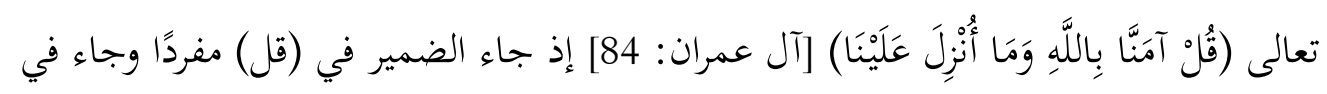
(آمنا) جمعًا، ويعلق الزخششري على ذلك بقوله: " أمر رسول الله - صلى الله عليه وسلم بأن يخبر عن نفسه وعمن معه بالإيمان، فلذلك وحد الضمير في (قل) وجمع في (عامنا)، ويجوز أن يؤمر بأن يتكلم عن نفسه كما يتكلم الملوك، إجلالًا من الله لقدر نبيه."

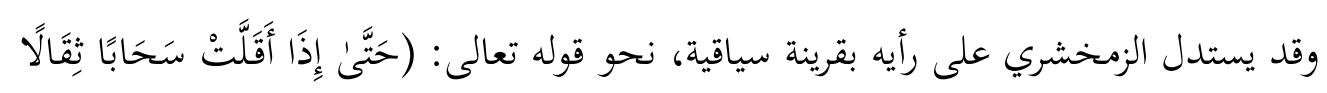
سُقْنَاهُ لِبَلَدِ مَيّتِ) [الأعراف: 57] فالضمير في (سقناه) جاء مذكرًا في حين أن المحال إليه مؤنث، بدلالة وصفه بكلمة (تقال)، وهنا يبين الزمخشري أن الضمير عاد حملاً على اللفظ

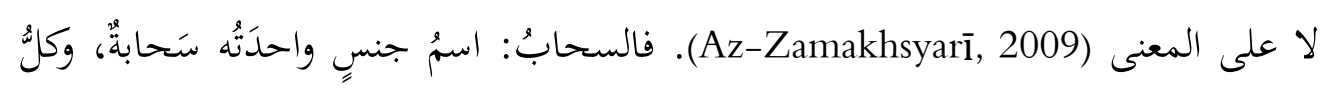
اسم جنس فيه لغتان: التذكير باعتبارِ اللفظِ والتأنيثُ باعتبارِ المعنى (Al-Halabi, n.d). وقد يرجع الرمخشري الضمير في حالة عدم مطابقته للمحال إليه على المعنى، لا على اللفظ

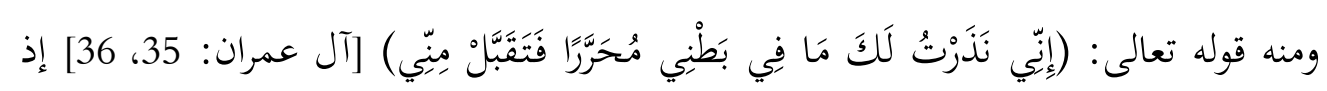
يعود الضمير في (فلما وضعتها) على (ما في) بطني، "وإنما أنث على المعنى؛ لأن ما في بطنها كان أنثى في علم الله، أو على تأويل الحبلة، أو النفس أو النسمة (Az-Zamakhsyarī).

$$
\text { اسم الإشارة }
$$

عني الزمخشري باسم الإشارة، فإنه عند وروده يحدد لمن يكون، ومن أمثلة ذلك ما جاء في

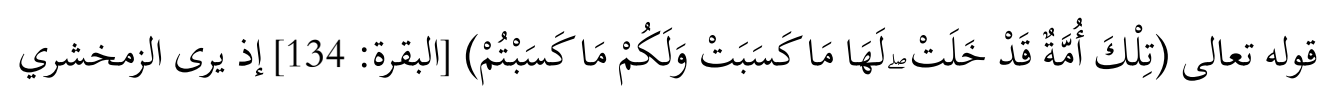
أن (تلك) إشارة إلى الأمة المذكورة التي هي إبراهيم ويعقوب وبنوهما الموحدون-Az) Zamakhsyarī, 2009). 
Osamah Saleh Mohammed Allbail, Rijal Mahdi

وقد لا تدل أسماء الإشارة على مشار إليه واحد، بل قد يتعلد المشار إليه نحو قوله تعالى:

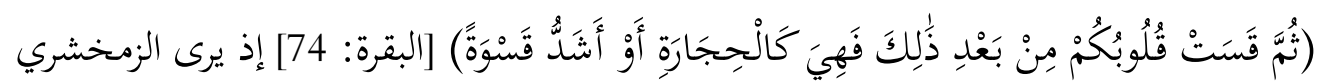
أن (ذلك) " إشارة إلى إحياء القتيل، أو إلى جميع ما تقدم من الآيات المعدودة -Az) فنحن هنا أمام تعدد للمشار إليه، فالاحتمال الأول: هو عودة الإشارة إلى عنصر سابق متقدم، وهو إحياء القتيل، أما الاحتمال الثاني فهو أن يعود إلى خطاب سابق، مكون من سبع آيات وهذا الاستحضار لخطاب بأكمله، يجعل الخطاب متماسگًا. (Al-Umusy, 2018)

وقد تمتد الإشارة إلى القرآن الكريم كله، ومن الأمثلة على ذلك قوله تعالى: (بٌ د ــ بأ ئا ئه ئه ئو ئو ئوُ ئوُ ئو ئوّ) [الجاثية: 11] فـ (هذا) إشارة إلى القرآن الكريم كله، ويستدل الزمخشري على ذلك بقوله تعالى: (والذين كفروا بآيات ربهم) (Az-Zamakhsyarī, 2009) معتمدًا في ذلك على السياق الداخلي للآية. وبما أن النص القرآني نص مقدس، وبه الأحكام التي يجب على المسلم التمسك بها ومنه استنبط العلماء فقهرم، فإن اختلاف تحديد المشار إليه، قد يؤدي إلى اختلاف فقهي بينهم، فقد نقل الزمخشري بعضًا من هذا الاختلاف، وذلك عند حديثه عن قوله تعالى:

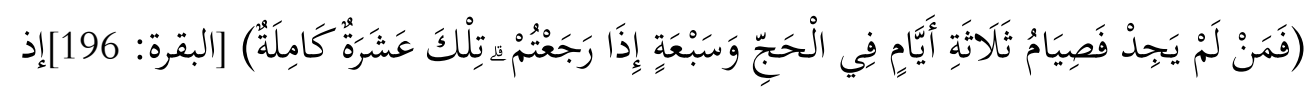
يقول: " (ذلك) إشارة إلى التمتع عند أبي حنيفة وأصحابه فلا متعة ولا قِران لحاضري المسجد الحرام عندهم، ومن تمتع منهم أو قرن كان عليه دم، وهو دم جناية لا يأكل منه وأما القارن والمتمتع من أهل الآفاق فدمهما دم نسك، يأكلان منه، وعند الشافعي إشارة إلى الحكم الذي هو وجوب الهدي أو الصيام، ولم يوجب عليهم شييًا (Az-Zamakhsyarī, 2009)، فاختلاف الفقيهين في تحديد المشار إليه، أدى بهما إلى استباط حكمين مختلفين. 
Osamah Saleh Mohammed Allbail, Rijal Mahdi

ومن الأمور التي ذكرها وبينها الزمخشري، هي عدم تطابق اسم الإشارة لما تشير إليه، ومن

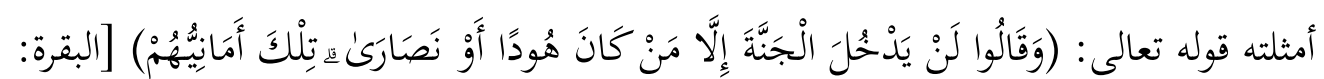
111] إذ يقول الزخشري: "فإن قلت لم قيل (تلك أمانيهم)، وقولهم: (لن يدخل الجنة) أمنية واحدة قلت أشير بها إلى الأماني المذكورة و[هي] أمنيتهم أن لا ينزل على المؤمنين خير من ربهم، وأمنيتهم أن يردوهم كفارًا وأمنيتهم أن لا يدخل الجنة غيرهم Az-Zamakhsyarī, (2009فالزمخشري يجعل الإشارة إشارة إلى عدة أماني مذكورة في عدة آيات، فالأمنية الأولى جاءت مذكورة في الآية (105)، والأمنية الثانية جاءت في الآية (109)، أما الأمنية الثالثة فقد جاءت في الآية (111)، والذي جعل الزمخشري يعود إلى تحديد هذه الأماني هو مجيء البدل (أمانيهم) دالًا على الجمع في حين أن ما سبقه كان مفردًا. ومن الأمثلة التي خالف فيها إسم الإشارة المشار إليه، قوله تعالى: (رَبَّنَا مَا خَلَقْتَتَ هُذَا بَاطِلاً سُبْحَانَكَ فَقِنَا عَذَابَ النَّارِ) [آل عمران: 191] إذ خالف اسم الإشارة (هذا) الذي يدل على المفرد المذكر المشار إليه (السموات والأرض)، وهنا يوضح الزمخشري عدم التطابق بقوله: "فإن قلت هذا إشارة إلى ماذا؟ قلت: إلى الخلق على أن المراد به المخلوق. كأنه قيل ويتفكرون في مخلوق السموات والأرض أي: فيما خلق منها، ويجوز أن يكون إثارة إلى السموات والأرض؛ لأنها في معنى المخلوق، كأنه قيل ما خلقت هذا المخلوق العجيب باطلاً، وفي هذا ضرب من التعظيم (Az-Zamakhsyarī, 2009). وقد تتعدد الإحالات داخل الآية الواحدة، ويصاحب ذلك التعدد تعدد في المشار إليه، ومن

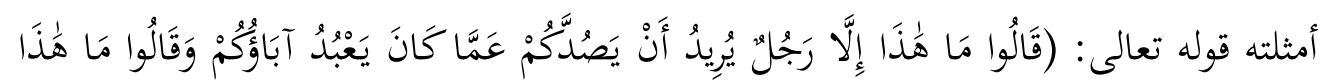

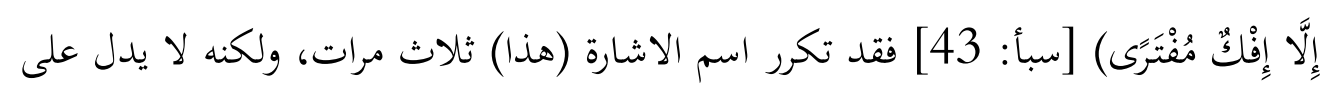
مشار إليه واحد إذ جاءت "الإشارة الأولى: إلى النبي (صلى الله عليه وسلم) ـ والثانية: إلى القرآن. والثالثة: إلى الحق (Az-Zamakhsyarī, 2009). 
Osamah Saleh Mohammed Allbail, Rijal Mahdi

وإذا كان المشار إليه في الأمثلة السابقة محددًا، وإن تعدد، فإنه قد يشار إلى مبهم، ومن أمثله

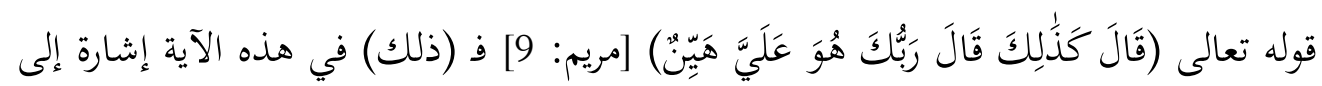
مبرهم يفسره (هُوَ عَلَكَّ هَيَّنُ) (Az-Zamakhsyarī, 2009).

ويقف الزمخشري عند استعمل اسم الإشارة المخصص للبعيد موضع اسم الإشارة المخصص

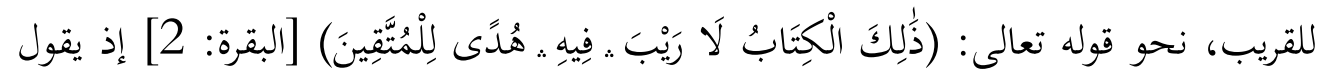
الزمخشري: فإن قلت: لم صحت الإشارة بذلك إلى ما ليس ببعيد؟ قلت وقعت الإشارة إلى (الم) بعد ما سبق التكلم به، وتقضى والمقضّى في حكم المتباعد، وهذا في كل كلام يحدث الرجل بحديث ثم يقول: وذلك ما لا شك فيه ويحسب الحاسب: ثم يقول فذلك كذا وكذا (Az-Zamakhsyarī, 2009). ثانيا: التكرار

وهو من عناصر الاتساق المعجمي وهو يعد حسب (شارول) من الروابط التي تصل بين العلاقات اللسانية(Buqarrah, 2009)، أما الزمخشري فيرى أن التكرار بحد ذاته حقيق بالاجتناب في البلاغة، ولكن إذا وقع لأجل غرض بلاغي يقصده المتكلم من تعظيم أو تهويل

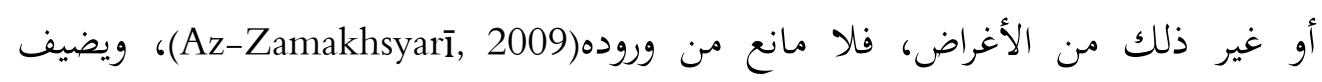
الزمخشري عند حديثه عن تكرار أحاديث الوعظ بقوله: ": النفوس أنفر شيء من حديث الوعظ والنصيحة، فما لم يكرر عليها عودًا عن بدء، لم يرسخ فيها ولم يعمل عمله، ومن ثم كانت عادة رسول الله - صلى الله عليه وسلم - أن يكرر عليهم ما كان يعظ به، وينصح ثلاث مرات. . . ليركزه في قلوبهم، ويغرسه في صدورهم (Az-Zamakhsyarī, 2009). ففائدة التكرار ينظر إليها بحسب موضوع الخطاب، وحالة المخاطب، فهما اللذان يستدعيان المتكلم أن يكرر الخطاب حتى يثبت وتقره النفوس. 
ومن الأمثلة التي تنبه فيها الزمخشري إلى ظاهرة التكرار وبين فائدته. قوله تعالى : (أُولْئِكَ عَلَّن

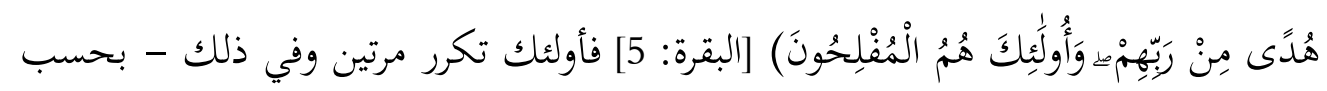

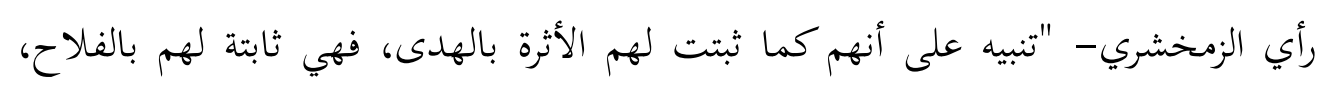
فجعلت كل واحدة من الأثرتين في تمييزهم بالمثابة التي لو انفردت كفت مميزة على حيالها

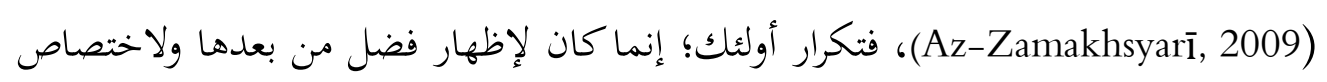
المؤمنين بهاتين الميزتين. ويرجع الزمخشري التكرار إلى نفسية المخاطب، ومدى تأثره بالخطاب، ومن أمثلته قوله تعالى:

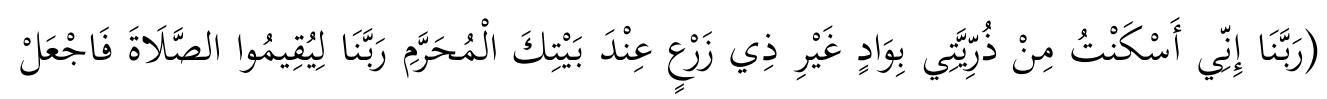

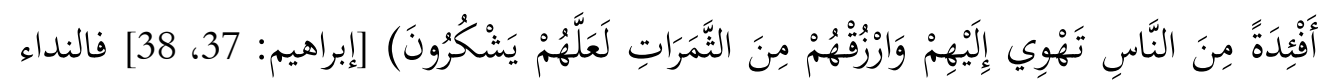
المكرر دليل التضرع واللجأ إلى الله تعالى(Az-Zamakhsyarī, 2009).

و يأتي التكرار أحيانًا دالًا على قبح عمل، وفيه حث لمن يقرأ ويسمع على الاعتبار والاتعاظ

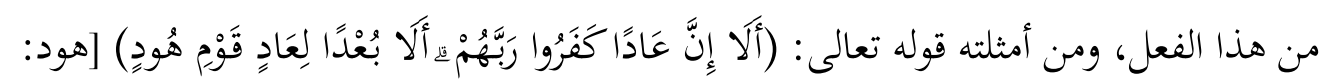
60] إذ يقول الزمخشري: " (ألا) وتكرارها مع النداء على كفرهم والدعاء عليهم، تهويل لأمرهم وتفظيع له، وبعث على الاعتبار بهم والحذر من مثل حالهم (Az-Zamakhsyarī, 2009).

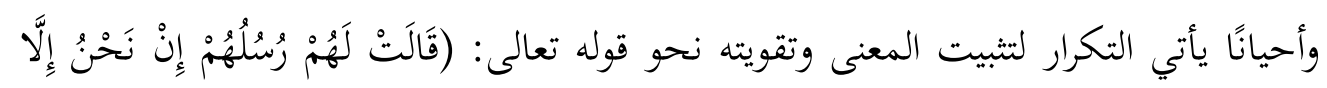

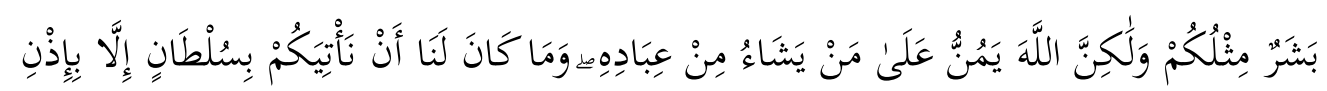

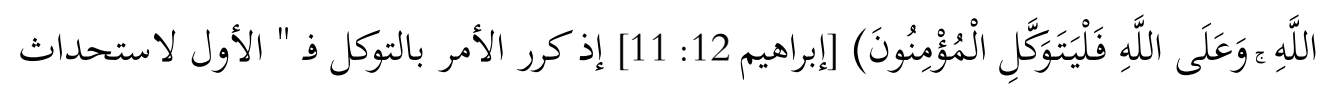
التوكل، وقوله: (فَلْيَتََكََّّلِ الْمُتَوَّكُونَ) معناه: فليثبت المتوكلون على ما استحدثوا من توكلهم وقصدهم إلى أنفسهم على ما تقدّم". وقد يكون التكرار لإضافة معنى، أو ترجيح فضل، نحو

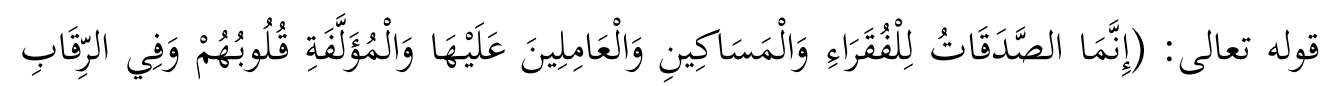

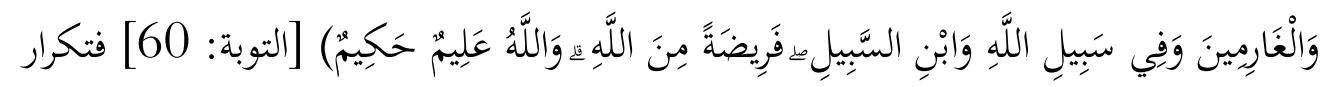


حرف الجر (في) في قوله: (وفي الرقاب) (وَفِى سَبِيلِ اللَّهِ) "فيه فضل ترجيح لهذين على الرقاب والغارمين (Az-Zamakhsyarī, 2009). وتكمن أهمية التكرار في قدرته على تنبيه السامع للإنصات وتجديد الاستماع عند كل خطاب،

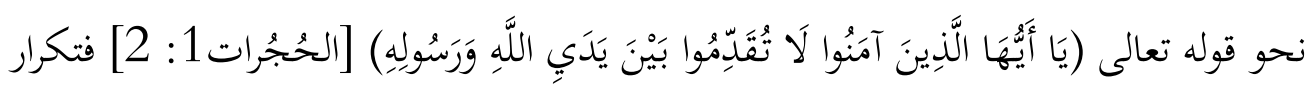
مناداة المؤمنين في الآية الثانية " استدعاء منهم لتجديد الاستبصار عند كل خطاب وارد، وتطرية الإنصات لكل حكم نازل، وتحريك منهم لئلا يفترقوا ويغفلوا عن تأملهم، وما أخذوا به عند حضور مجلس رسول الله (صلى الله عليه وسلم) من الأدب الذي المحافظة عليه تعود عليهم بعظيم الجدوى في دينهم (Az-Zamakhsyarī, 2009). ففي التكرار تجديد للاستماع وفيه اهتمام بالخطاب، وأن هذا الكلام الملقى له أهمية ينبغي عدم إغفالها، بل يجب التركيز عليها.

وقد يأتي التكرار مناسبًا للمعنى، فتكرار اللفظ دليل على تكرار المعنى، نحو قوله تعالى: (كى ك ك گ گ) [الشعراء: 94] "تكرير الكب، جعل التكرير في اللفظ دليلاً على التكرير في المعنى، كأنه إذا ألقى في جهنم ينكب مرة بعد مرة حتى يستقرّ في قعرها-Az). Zوليست كل مماثلة في الألفاظ تكرارًا عند الزمخشري، إذ قد يأتي اللفظ مماثلًا ولا يمثل تكرارًا، بل يكون مجيئه ناتجًا عن حذف، مثل قوله تعالى (إذْ قَالَ

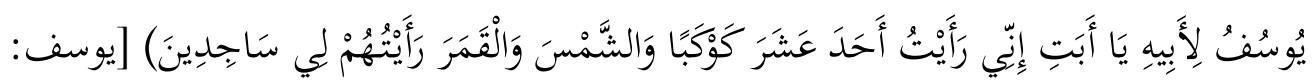

يقول الزمخشري ". فإن قلت: ما معنى تكرار رأيت قلت: ليس بتكرار، إنما هو كلام مستأنف على تقدير سؤال وقع جوابًا له، كأن يعقوب عليه السلام قال له عند قوله: (يأَبتِ إنّى رَأَيْتُ

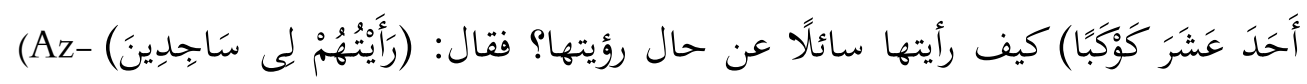


Osamah Saleh Mohammed Allbail, Rijal Mahdi

فالزمخشري هنا يفترض وجود حوار دار بين الاب وابنه فكانت إجابة Zamakhsyarī, 2009). يوسف عن السؤال بقوله: رأيتهم.

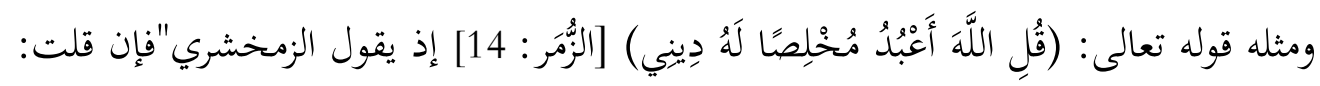

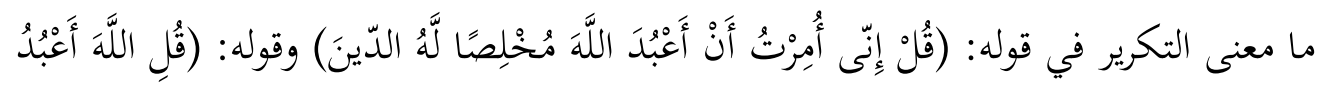
هُخْلِصًا لَّهُ دِينى) قلت: ليس بتكرير؛ لأنّ الأوّل إخبار بأنه مأمور من جهة الله بإحداث العبادة والإخلاص. والثاني: إخبار بأنه يختص الله وحده دون غيره بعبادته مخلصًا له دينه -Az) فالسياق هو وحده من يحكم على التكرار من عدمه، فاللفظ الواحد Zamakhsyarī, 2009). لا يكفي لمعرفة التكرار، ومن ذلك تكرار كلمة الصالاة في قوله تعالى (الَّنِينَ هُمْ فِي صَالَتِهِمْ خَاشِعُونَ) [المؤمنون: 2] وقوله تعالى : (وَالَّذِينَ هُمْ عَلَّن صَلَوَاتِهِمْ يُحَافِظُونَ) [المؤمنون: 9 فذكر الصلاة مرتين لايعني دلالتهما على معنى واحد "فهما ذكران مختلفان، فليس بتكرير. وصُفوا أَوَلاً بالخشوع في صلاتهم، وآخرًا بالمحافظة عليها (Az-Zamakhsyarī, 2009). ثالثا: العطف أولى الزمخشري العطف عناية فائقة، فقد تتبعه بكل أنواعه، فبين عطف الكلمة على الكلمة، و عطف الجملة على الجملة، وعطف الكلام على الكلام، وبين المعنى المترتب على ذلك، ومن إشارته إلى العطف و ملاءمته للسياق، قوله عند تفسير قوله تعالى: (وَبَثَبّرِ اللَّنِينَ آمَنُوا

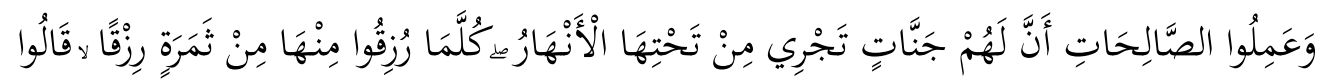

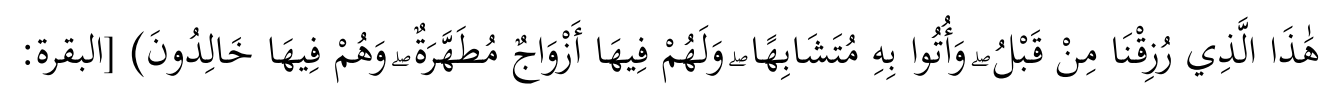
25] إذ يقول "فإن قلت علام عطف هذا الأمر، ولم يسبق أمر ولا نهي يصح عطفه عليه؟ قلت: ليس الذي اعتمد بالعطف هو الأمر حتى يطلب له مشاكل من أمر أو نهي يعطف عليه، إنما المعتمد بالعطف هو جملة وصف ثواب المؤمنين فهي معطوفة على جملة وصف 
Osamah Saleh Mohammed Allbail, Rijal Mahdi

عقاب الكافرين(Az-Zamakhsyarī, 2009) ، فالذي سوغ العطف هو محتوى الوصفين الذي يحمل دلالة التضاد.

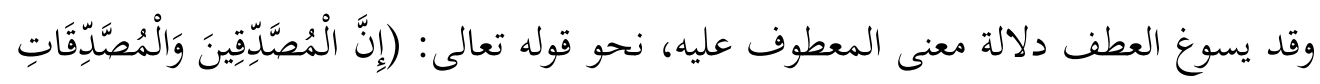

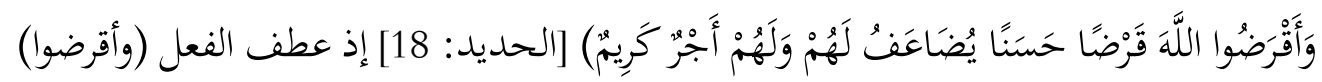
على اسم الفاعل (المصدقين)، ويرجع الزمخشري ذلك إلى أن اسم الفاعل يدل ": على معنى الفعل في المصدّقين؛ لأنّ اللام بمعنى الذين، واسم الفاعل بمعنى أصدقوا، كأنه قيل: إنّ الذين أصدقوا وأقرضوا (Az-Zamakhsyarī, 2009). فاسم الفاعل (المصدقين) يحمل معنى الفعل، وهو فعل التصدق ودلالته على هذا هي التي سوغت أن يعطف عليه الفعل الماضي (وأقرضوا). ومن ذلك قوله تعالى:

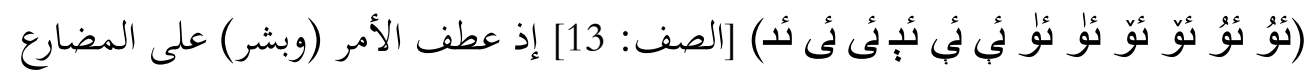

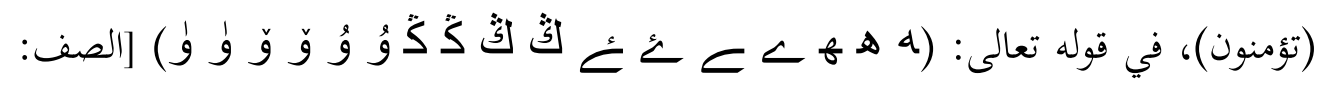
11] وفي ذلك يقول الزمخشري "فإن قلت: علام عطف قوله (وَبَشُّرِ الْمُوِْْمِينَ) ؟ قلت: على (تُوْْمنُونَ) لأنه في معنى الأمر، كأنه قيل: آمنوا وجاهدوا يثبكم الله وينصركم، وبشر يا رسول الله المؤمنين بذلك (Az-Zamakhsyarī, 2009). وهو بهذا يشير إلى قوله تعالى: (تؤمنون بالله) فالفعل (تؤمنون) يدل على الأمر بدلالة قراءة ابن مسعود (آمنوا بالله) Khlawaih) (2009، وكذلك دلالة الخطاب فالخطاب موجه من الله عزوجل إلى عباده المؤمنين.

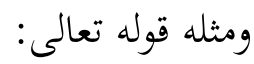

(U U ثُ ث) [العاديات: 4] حيث سبق الفعل اسم الفاعل (المغيرات)، ولذا جاز أن يعطف عليه؛ لأنه وضع موضع الفعل؛ فإنّ المعنى كما يرى الزمخشري هو "واللاتي عدون فأورين، فأغرن فأثرن(Az-Zamakhsyarī, 2009). 
Osamah Saleh Mohammed Allbail, Rijal Mahdi

ويرى الزمخشري إمكانية عطف شبه الجملة على الضمير المتصل، نحو قوله تعالى: (وَإِذٍ

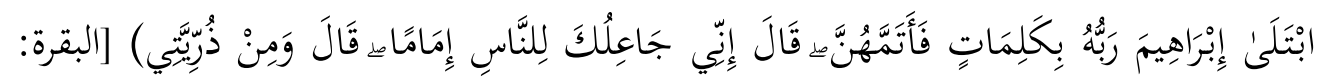
124] إذ يشير الزمخشري إلى أن (ومن ذريتي) عطف على الكاف في (جاعلك)، كأنه قال: وجاعل بعض ذريتي، كما يقال: سأكرمك فتقول وزيداً (Az-Zamakhsyarī, 2009). بيد أنه يرى في موضع آخر، أنه لا يجوز أن يعطف (المسجد الحرام) على الهاء في (به) في قوله

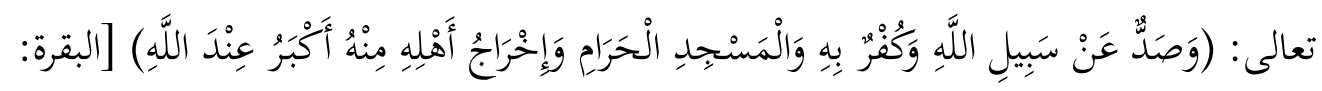
217] بل يرجعه إلى أنه عطف على الاسم الذي قبله، وهو (سبيل الله)، والذي سوغ إمكانية العطف على الضمير في الآية الأولى، هو السياق الحواري الذي جاء فيه ذلك الوصف، أما في الآية الثانية فلا وجود للسياق الحواري.

ونجد أن الزمخشري يفتح الباب أمام إمكانية تعدد المعطوف عليه، وهذا يعني تعدد الدلالة،

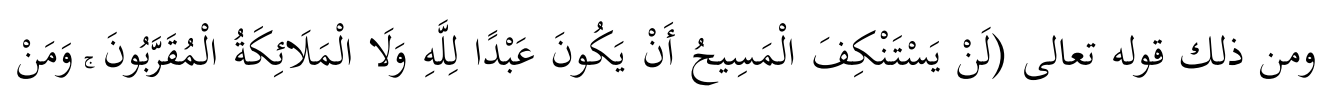

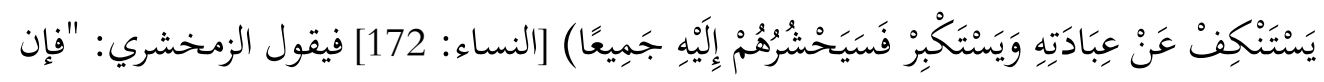
قلت علام عطف قوله (ولا الملائكة) ؟ قلت: لا يخلو إما أن يعطف على المسيح، أو على لى

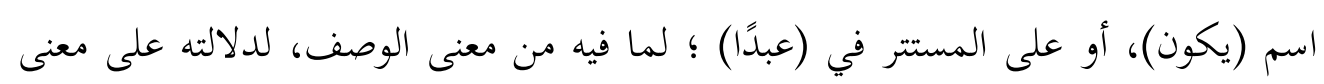
العبادة، كقولك: مررت برجل عبد أبوه، فالعطف على المسيح هو الظاهر لأداء غيره إلى ما فيه بعض انحراف عن الغرض، وهو أن المسيح لا يأنف أن يكون هو ولا من فوقه موصوفين بالعبودية، أو أن يعبد الله هو ومن فوقه" فنحن هنا أمام ثلاثة احتمالات الأول: عطف المالئكة على المسيح، فيكون المعنى لن يستنكف المسيح والملائكة أن يكونوا عبادًا لله، وهو الأرجح، لأن الغرض الذي قيل من أجله الخطاب هو عدم تأنف المسيح من أن يكون عبدًا لله. أما الاحتمال الثاني: فهو عطف الملائكة على اسم يكون، فيكون المعنى اتصاف عيسى 
والملائكة بالعبودية. أما الاحتمال الثالث فهو عطف الملائكة على الضمير المستتر في

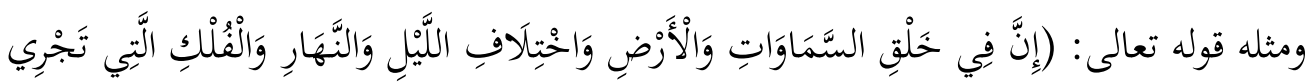

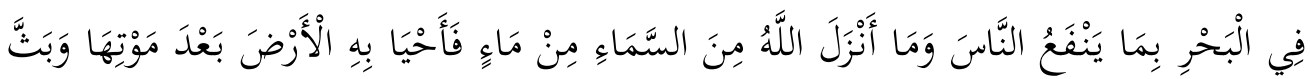

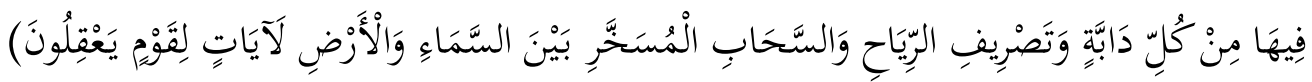
[البقرة: 164] يقول الزخشري منسائلاً: " قوله (وبث فيها) عطف على أنزل أم أحيا؟ قلت: الظاهر أنه عطف على أنزل داخل تحت حكم الصلة؛ لأن قوله: (فأحيا به الأرض) عطف على أنزل، فاتصل به وصارا جميعًا كالشيء الواحد، فكأنه قيل: وما أنزل في الأرض من ماء وبث فيها من كل دابة. ويجوز عطفه على أحيا، على معنى فأحيا بالمطر الأرض، وبث فيها من كل دابة. لأنهم ينمون بالخصب ويعيشون بالحيا (Az-Zamakhsyarī, 2009). فالعطف كي هنا يقوم على احتمالين الأول: أن (وبث) معطوف على (أنزل) وهنا تكون كل جملة مستقلة، وإنما يشتركا بالفاعل، أما الاحتمال الثاني: فهو عطفه على (أحيا)، وهنا تكون العلاقة سبية، فبسب الماء تكون حياة المواشي والدواب-Syihab al-Din al-Sayyid Mahmud al). Baghdadi, 1994) ومن اهتمامه بالعطف إشارته المتكررة إلى دلالة حروف العطف، ومن أمثلته قوله تعالى : (أَفَّنْ

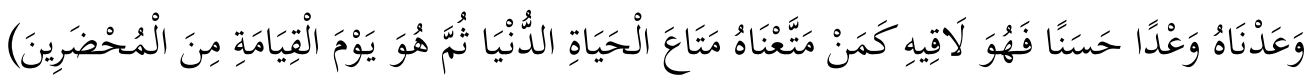
[القصص: 61] ففي الآية ثلاث جمل معطوفة، اثنتان منها بالفاء والثالثة بثم، وهنا يشير الزخشري إلى أنه قد ذكر في الآية التي قبلها متاع الحياة الدنيا، وما عند الله وتفاوتهما،

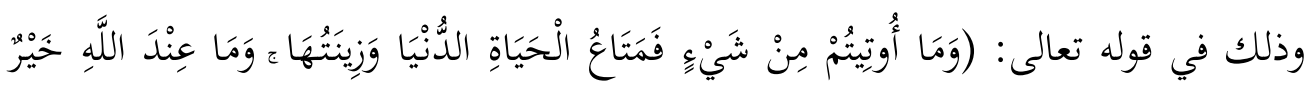

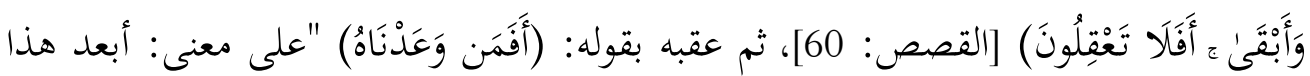
التفاوت الظاهر يُسوّي بين أبناء الآخرة وأبناء الدنيا، فهذا معنى الفاء الأولى، وبيان موقعها. 
Osamah Saleh Mohammed Allbail, Rijal Mahdi

وأمّا الثانية فللتسبيب؛ لأن لقاء الموعود مسبب عن الوعد، الذي هو الضمان في الخير. وأمّا (ثم) فلتراخي حال الإحضار عن حال التمتيع، لا لتراخي وقته عن وقته (Az-Zamakhsyarī). (2009فالعطف الأول هو لإنكار الشبه بين متاع الدنيا، وما عند الله، وأما الفاء الثانية فهي نتيجة مترتبة، فحصول متاع الله مترتب عن الوعد، أما معنى ثم، فلإظهار الفارق بين حال الإنسان ومنزلته بين الناس، وحاله عند الإحضار يوم القيامة وهو مهين. ومن الأمثلة التي يبين الزمخشري فيها دلالة حروف العطف، قوله تعالى: (كَيْفَ تَكْفُرُونَ بِاللَّهِ

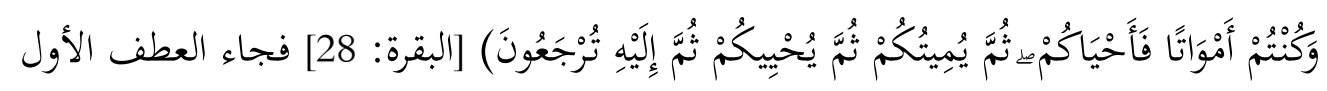
بالفاء والإعقاب بثم، وهنا يوضح الزمخشري السبب في ذلك ذلك بقوله: لأن الإحياء الأول قد تعقب الموت بغير تراخ، وأما الموت فقد تراخى عن الإحياء، والإحياء الثاني كذلك متراخ عن الموت، إن أريد به النشور تراخيًا ظاهرًا، وإن أريد به إحياء القبر، فمنه يكتسب العلم بتراخيه، والرجوع إلى الجزاء أيضًا متراخ عن النشور (Az-Zamakhsyarī, 2009) قد علل اختلاف حرف العطف - هنا - تعلياً نحويًا فثم تفيد الترتيب بالتراخي في حين تفيد الفاء الترتيب بالتعقيب.

وأحيانا يستطرد الزمخشري في بيان أسباب اختلاف استخدام حروف العطف، ودلالة كل

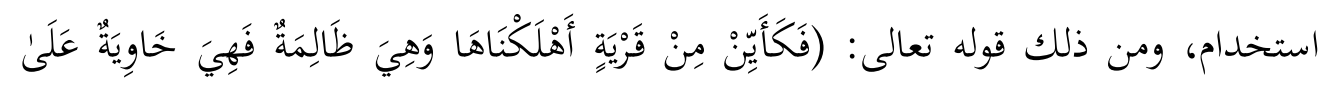

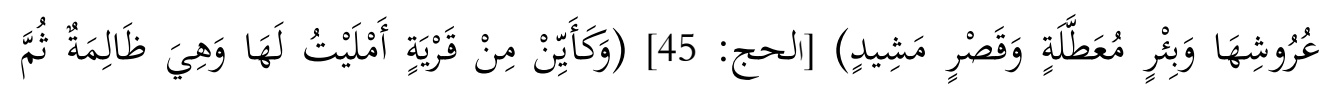
أَخَذْتُهَا وَإِلَيَّ الْمَصِيرُ) [الحجر: 48] حيث عطفت الآية الأولى بالفاء (فكأين)، في حين عطفت الآية الثانية بالواو (وكأين)، ويبين الزمخشري سبب ذلك، فيقول: " الأولى وقعت بدلاً عن قوله: (فَكَيْفَ كَانَ نَكِيرِ)، أما هذه فحكمها حكم ما تقدمها من الجملتين المعطوفتين بالواو، وهو قوله (ولن يخلف الله وعده).(Az-Zamakhsyarī, 2009) فالعطف محكوم 
Osamah Saleh Mohammed Allbail, Rijal Mahdi

بالعلاقات الداخلية في كل آية، فالآية الأولى مسبوقة بجمل عطفت بالفاء، أما الآية الثانية فقد سبقت بجمل معطوفة بالواو. ويبين الزخشري - أحيانًا - سبب اختيار أحد حروف العطف بدلًا من الحرف الآخر، ومن ذلك قوله تعالى : - ملى

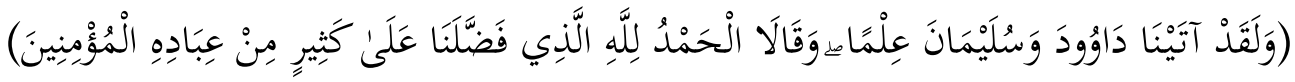
[النمل: 15] إذ يقول "فإن قلت: أليس هذا موضع الفاء دون الواو، كقولك: أعطيته فشكر، ومنعته فصبر؟ قلت: بلى، ولكن عطفه بالواو إشعار بأن ما قالاه بعض ما أحدث فيهما إيتاء العلم وشيء من مواجبه، فأضمر ذلك، ثم عطف عليه التحميد، كأنه قال: ولقد آتيناهما علمًا،

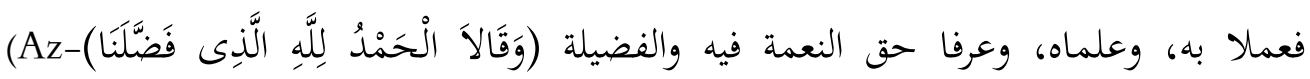
فالعطف بالواو فيه إشعار بأن هنالك كلامًا لم يقل و وأن ما ذكر Zamakhsyarī, 2009). هو بعضه.

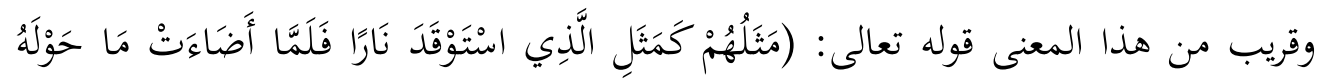

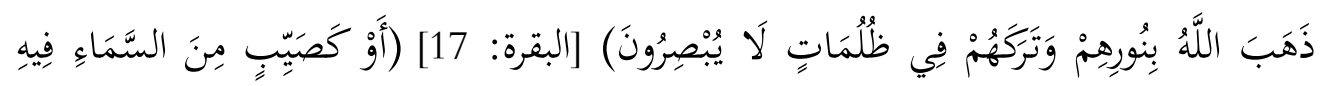

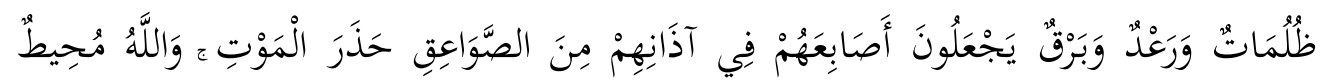
بِالْكَافَِِِِ) [البقرة: 19] إذ يقول "فإِن قلت لم عطف أحد التمثيلين على الآخر بحرف الشك؟ قلت: أو في أصلها لتساوي شيئين فصاعدًا في الشك، ثم اتسع فيها، فاستعيرت للتساوي في غير الشك، وذلك قولك: جالس الحسن أو ابن سيرين تريد أنهما سيان في استصواب أن يجالسا. ومنه قوله تعالى: (ولا تطع منهم آثمًا أو كفورًا) الانسان 24 أي: الآثم والكفور متساويان في وجوب عصيانهما، فكذلك قوله (أو كصيب) معناه أن كيفية قصة المنافقين مشبهة لكيفيتي هاتين القصتين، وأن القصتين سواء في استقلال كل واحدة منهما بوجه 
Osamah Saleh Mohammed Allbail, Rijal Mahdi

(Az-Zamakhsyarī, التمثيل، فبأيتهما مثلتها فأنت مصيب وإن مثلتها بهما جميعًا فكذلك 2009).

ومن اهتمامه في رصد العطف في السياق الداخلي، إشارته إلى عدم اقتران حرف العطف في كلمات، ومجيئه في البعض الآخر، نحو قوله تعالى: (عَسَنى رَبُّهُ إِنْ طَلَََّكُنَّ أَنْ يُبْدِلَلهُ أَزْوَاجًا

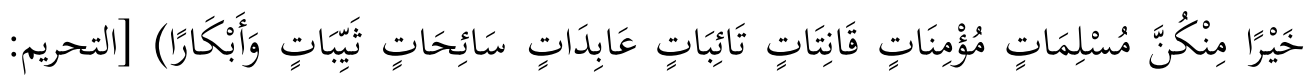
5]فقد جاءت الصفات الأولى كلها بدون عطف في حين توسط حرف العطف (ثيبات و ابكار)، ويرجع الزمخشري ذلك إلى كونهما صفتين متنافيتين، لا يجتمعن فيها اجتماعهن في سائر الصفات، فلم يكن بد من الواو . فالتضاد هو سبب مجيء (Az-Zamakhsyarī, 2009) الواو، مع أن بعض العلماء يشيرون إلى أن الواو هنا واو الثمانية حيث تعدت سبع صفات ففصل بين السبع الأولى والثامنه بالواو . وبلغ في اعتنائه بالعطف أنه يتتبع استخدم كلمة في السياق القرآني كله، ومن ذلك قوله تعالى (ئو) حيث وردت في القرآن بالعطف وورد استخدمها بدون العطف، ويفسر الزمخشري ذلك بقوله "إن قلت ما بال " يسئلونك " جاء بغير واو ثلاث مرات، ثم مع الواو ثلاثًا؟ قلت: كان سؤالهم عن تلك الحوادث الأول وقع في أحوال متفرقة، فلم يؤت بحرف العطف؛ لأن كل واحد من السؤالات سؤال مبتدأ، وسألوا عن الحوادث الأخر في وقت واحد، فجيء بحرف الجمع لذلك، كأنه قيل: يجمعون لك بين السؤال عن الخمر والميسر والسؤال عن الإنفاق والسؤال عن كذا وكذا (Az-Zamakhsyarī, 2009)

الخلاصة

على الرغم من أن الزمخشري لم يذكر لفظ السياق إلا بضع مرات، إلا أنه استخدمه كثيرًا أثناء تفسيره، فقد تناول معظم الظواهر السياقية تناولًا يكشف عن إدراك الزخششري لأهمية السياق في فهم المعنى.أدرك الزمخشري أهمية تماسك النص، وما يحدثه التكرار 
Osamah Saleh Mohammed Allbail, Rijal Mahdi

والإحالة من ربط النص بعضه ببعض. وقد اعتنى بالمحال والمحال إليه وبتعدد المحال إليه، والذي يؤدي إلى ترابط النص، فهذا لا يعني أنه قد تركه دون ضابط أو قيد إذ يشدد على أهمية مراعاة السياق الداخلي، ومراعاة النظم القرآني، ولكن الباحث لاحظ أن الزمخشري حينما تناول ظاهرة التكرار تناوله من جانب المعنى، ووظيفته اللغوية، وفائدته بالنسبة للمخاطب، إذ يرى الزمخشري أن التكرار يعد لغوًا إلا إذا أفاد فائدة للقارئ، أو أراد المتكلم إيصال رسالة للقارئ من خلاله. اهتم الزمخشري اهتمامًا كبيرًا بالعطف، وبين الزمخشري قدرة العطف على ربط أجزاء النص، ولم يكتف بذلك بل إنه كان يحدد دلالة حروف العطف وأسباب اختيارها.

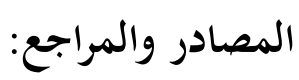

Ahmed, K. M. (2017). The Significance of The Methodological Choice Between The Multiplicity of Alternatives and The Appropriate Context in The Holy Quran. Journal of Al-Frahedis Arts, 28(2), 26-47. https://doi.org/http://dx.doi.org/10.25130/art.v2i28

Al-Anbari, M. B. A.-Q. (1987). Kitab Al-Addhaad (M. A. A.-F. Ibrahim (ed.)). Al-Maktabah Al-A`shriyah.

https:/ / ia802609.us.archive.org/23/items/FP1514/1514.pdf

Al-Bustani, B. H. (2011). The Concept of Text and the Textual Standards of the Holy Quraan A Theoretical Study. Majallah Abhas Kulliyah At-Tarbiyah Al-Asasiyah, 11(1), 174-196. https:/ / doi.org/ISSN: 19927452

Al-Halabi, A. B. Y. A.-M. B. (n.d.). Ad-Durru Al-Mashun Fi Ulumi AlKitab Al-Maknun (1st ed.). Dar Al-Qalam.

https://ia902608.us.archive.org/2/items/FP5635/dmokm01.pdf

Al-Jalil, M. A. (2001). Ilm Ad-Dalalah Ushuluhu Wa Mabahitsuhu Fi At-Turats Al-A`rabiy (1st ed.). Arab Writer Union. https://ia801604.us.archive.org/12/items/lisgroup31/book1_1861.pdf

Al-Mihana, H. A. H. (2017). Miracles Expressionist Locate In Surat 
ALwaqiea (Text Cohesion Model). Journal Of Babylon Center for Humanities Studies, 7(4), 102-123. https:/ / doi.org/ ISSN 2227289523130059

Al-Umusy, K. (2018). Al-Khitab Al-Qurani Dirasah Fi Al-Alaqah Baina An-Nash Wa As-Shiyaq (1st ed.). Jidaran Lil Kitab Al-A`lami, A'lam Al-Kutub Al-Hadis.

https:/ / arablib.com/ ?view=book\&lid=2\&rand1=WEpXc2pSOW 00S3Jo\&rand2=V3pRQllqeHJ0SEcz

Al-Zyout, A. (2019). Al-Zamakhshari's Treatment of the Quranic Diversification of Discourse according to the Number of Addresses In his Interpretation. DIRASAT: SHARI'A AND LAW SCIENCES, 46(1), 329-343.

https://journals.ju.edu.jo/DirasatLaw/article/view/15821

Az-Zamakhsyarī, M. (2009). Tafsir Al-Kassyaaf A`n Haqaiq At-Tanzil Wa Uyun Al-Aqawil Fii Wujuh At-Takwil (K. M. Syiha (ed.); 3rd ed.). Dar Al-Marefah.

https://ia803004.us.archive.org/3/items/WAQ121740/121740.p $\mathrm{df}$

Bakhulah, B. (2018). Mazhahir Tamasuk An-Nash Al-Qurani

Wanashssiyatuhu Dirasah Bayaniyah Dilaliyah. Majallah Dirasat, 7(1), 59-67. https://www.asjp.cerist.dz/en/article/38547

Budar`u, A. (n.d.). Manhaj As-Siyaq Fii Fahm An-Nash (111th ed.). Kitabul Ummah-Wizarah Auqaf Wa As-Syuun Al-Islamiyah, Qatar. https://ecat.kfnl.gov.sa/hip/content/380778.pdf

Buqarrah, N. (2009). Al-Musthalahat Al-Asasiyah Fii Lisaniyat AnNash Wa Tahlil Al-Khitab: Dirasah Mu jamiyah (1st ed.). Jidaran Lil Kitab Al-A lami, A`lam Al-Kutub Al-Hadis.

https:/ / www.noor-book.com/-كتاب-المصطلحات-الاساسيه-في-لسانيات النص-و-تحليل-الخطاب-د-نعمان-بوقره

Faraj, B. (2019). Al-Ibda`Fii Ba`dhi Kitabat Az-Zamakhsyari Wa Abi Hayyan Dirasah Muqaranah. BAU Journal - Society, Culture \& Human Behavior, 1(1).

https://digitalcommons.bau.edu.lb/cgi/viewcontent.cgi?article= 1017\&context=schbjournal 
Osamah Saleh Mohammed Allbail, Rijal Mahdi

Khlawaih, I. (2009). Mukhtashar Fii Syawaz Al-Quran Min Kitab AlBadi' (1st ed.). Maktabah Al-Mutanabbi. https://archive.org/details/mfsquran

Syihab al-Din al-Sayyid Mahmud al-Baghdadi, A.-A. (1994). Ruh AlMa'ani Fii Tafsir Al-Quran Al-Azim Wa As-Sab`u Al-Masani. Dar Ihya At-Turas Al-Arabi. https://archive.org/details/waq0094 
Osamah Saleh Mohammed Allbail, Rijal Mahdi

This Page Is Intentionally Left Blank

تركت هذه الصفحة فارغة عمدا

'Halaman Ini Sengaja Dikosongkan' 